\title{
A Generic Cost Estimating Approach for a Composite Manufacturing Process Assessment
}

\author{
Justyna RYBICKA ${ }^{1}$, Teresa PURSE and Brett PARLOUR ${ }^{\mathrm{a}}$ \\ ${ }^{a}$ The Manufacturing Technology Centre, CV79JU, Coventry, UK
}

\begin{abstract}
Cost estimation helps build confidence in the feasibility of the development of novel manufacturing processes. This paper focuses on the exploration of the cost estimation for novel manufacturing processes for decision support. One of the aspects of estimation is building credibility around the analysis, especially, in the early stages of planning. Cost estimating guidelines provide a good overview of the cost estimation steps but there is a requirement for guidelines for cost estimation model development. Through building on an understanding of the cost estimation principles, as well as cost estimation modelling, a high-level generic approach for process cost estimation is proposed. Further, a demonstration of a cost estimation modelling approach used for composites manufacturing in the automotive sector is provided, outlining the steps in cost estimation model development.
\end{abstract}

Keywords. Cost estimation, composites manufacturing, benchmarking, cost drivers, process cost model.

\section{Introduction}

With the increasing drive to be competitive in ever-changing economic conditions, decision support tools are critical to enable the development of new manufacturing capability [1]. The ability to estimate costs with sufficient confidence in early phases of project provides an essential benefit to prove feasibility of new technologies.

In order to be credible to support decision making and provide decision-makers with confidence, the cost estimation process requires sufficient governance. Currently, there are many publications that cover cost estimating approaches but very little is published regarding cost modelling approaches and governance. This paper explores a process cost estimation approach that is based on cost estimation principles as well as a generic approach for cost estimation modelling. Further, a demonstration of a cost estimation modelling approach used for composites manufacturing in the automotive industry is provided as a use case.

\footnotetext{
${ }^{1}$ Corresponding Author. justyna.rybicka@the-mtc.org
} 


\section{Review of existing process cost estimation}

This section covers a review of the existing composites manufacturing process cost estimation literature.

The review of literature uncovered that cost estimation is used in automotive, aerospace and renewable energy industries and the main reasons for process cost estimation are, supporting business cases [3, 4,10], process benchmarking [5, 6, 7], product design [2] and design vs. manufacturing process trade-offs [8, 9].

Standardised guidelines for cost estimation have been developed by U.S. Government Accountability Office (GAO) [13] and National Aeronautics and Space Administration (NASA) [14]. The key focus of these guidelines is the information required to capture and what processes are needed to provide a reliable cost estimate. Evaluation of the credibility of a model is a critical factor to providing robust and fit for purpose analysis. Multiple authors agree that there is a limited number of reviews that compare the methods used in different cost estimation models [11, 12]. One of the challenges in cost estimation is the evaluation of the reliability of the approach taken to build the model.

Although standardised guidelines for cost estimation are defined, there is a lack of published methodologies for developing models that support cost estimation. The development of models to support cost estimation requires a further level of understanding. An assessment of existing studies (Table 1) identified that it is a challenge to ascertain a standardised cost modelling approach, as the described approach is often incomplete.

Table 1. Assessment of existing cost estimation approaches for composites manufacturing for approach completeness

\begin{tabular}{|c|c|c|c|c|c|c|c|c|}
\hline \multicolumn{3}{|c|}{$\begin{array}{cc}\text { Author } & \begin{array}{c}\text { What is } \\
\text { the } \\
\text { business } \\
\text { question } \\
?\end{array} \\
\end{array}$} & \multirow[t]{2}{*}{$\begin{array}{l}\text { What is the } \\
\text { scope of the } \\
\text { estimate } \\
\text { model? } \\
x\end{array}$} & \multirow[t]{2}{*}{$\begin{array}{l}\text { What data } \\
\text { is } \\
\text { required? } \\
x\end{array}$} & \multirow[t]{2}{*}{$\begin{array}{r}\text { What and } \\
\text { how is the } \\
\text { estimate } \\
\text { delivered? } \\
x\end{array}$} & \multirow[t]{2}{*}{$\begin{array}{l}\text { How is the } \\
\text { estimate } \\
\text { evaluated? } \\
x\end{array}$} & \multirow[t]{2}{*}{$\begin{array}{l}\text { What and } \\
\text { how is } \\
\text { analysis } \\
\text { performed } \\
? \quad x\end{array}$} & \multirow[t]{2}{*}{$\begin{array}{r}\text { Number } \\
\text { of sections } \\
\text { covered }\end{array}$} \\
\hline She & & $\mathbf{x}$ & & & & & & \\
\hline Hagnell and A & o [6] & $\mathbf{x}$ & $\mathbf{x}$ & $\mathbf{x}$ & & & $\mathbf{x}$ & 4 \\
\hline Haf & & $\mathbf{x}$ & $\mathbf{x}$ & $\mathbf{x}$ & $\mathbf{x}$ & & $\mathbf{x}$ & 5 \\
\hline & & $\mathbf{x}$ & & $\mathbf{x}$ & $\mathbf{x}$ & $\mathbf{x}$ & $\mathbf{x}$ & 5 \\
\hline Che & & $\mathbf{x}$ & $\mathbf{x}$ & & $\mathbf{x}$ & & & 3 \\
\hline $\mathrm{Cur}$ & & $\mathbf{x}$ & $\mathbf{x}$ & $\mathbf{x}$ & $\mathbf{x}$ & $\mathbf{x}$ & $\mathbf{x}$ & 6 \\
\hline Sch & & & $\mathbf{x}$ & $\mathbf{x}$ & $\mathbf{x}$ & & $\mathbf{x}$ & 4 \\
\hline Mårten & & $\mathbf{x}$ & $\mathbf{x}$ & $\mathbf{x}$ & & & $\mathbf{x}$ & 4 \\
\hline & & $\mathbf{x}$ & $\mathbf{x}$ & $\mathbf{x}$ & & & $\mathbf{x}$ & 4 \\
\hline $\mathrm{Ha}$ & & & $\mathbf{x}$ & & $\mathbf{x}$ & & $\mathbf{x}$ & 3 \\
\hline & & 8 & 9 & 8 & 7 & 3 & 9 & \\
\hline
\end{tabular}

The challenges to ascertain the cost estimation modelling approaches are that $[8,4]$ :

- focus is usually on the case study and application, and not on the approach

- focus on different scopes (i.e. different product lifecycle phases are considered)

- there is confidentiality around data

- models are often specific to the application and the subjectivity of the cost estimator

In order to support the standardisation of the model development, a generic approach for cost estimation is presented in the next section of this paper. 


\section{Generic cost estimation approach}

This section outlines a generic approach for cost estimation modelling for automotive composites manufacturing. It consists of steps outlined in Table 2.

Table 2. Generic Approach to the Development of Cost Estimation Models

\begin{tabular}{ll}
\hline $\begin{array}{l}\text { Cost Estimation } \\
\text { Phase }\end{array}$ & Definition \\
\hline Requirements Capture & $\begin{array}{l}\text { Build an understanding of the aim of the estimate by capturing the business } \\
\text { questions and the client requirements }\end{array}$ \\
\hline Concept Model & $\begin{array}{l}\text { Develop a concept model capturing the model scope, boundaries and } \\
\text { assumptions }\end{array}$ \\
\hline Model Development & Build the model using best practice principles \\
\hline Testing & Validate and verify the model to determine it is fit for purpose \\
\hline Analysis & $\begin{array}{l}\text { Populate the model with appropriate, reliable, referenced data. Specify the } \\
\text { type of analysis performed. Evaluate the resulting estimate and produce } \\
\text { suitable reports }\end{array}$ \\
\hline
\end{tabular}

\section{Use case}

Based on the generic approach steps, a cost estimation model for composites manufacturing in the automotive industry has been developed. The use case was focused on supporting a business case for manufacturing components using novel processes. The approach is outlined in Figure 1.

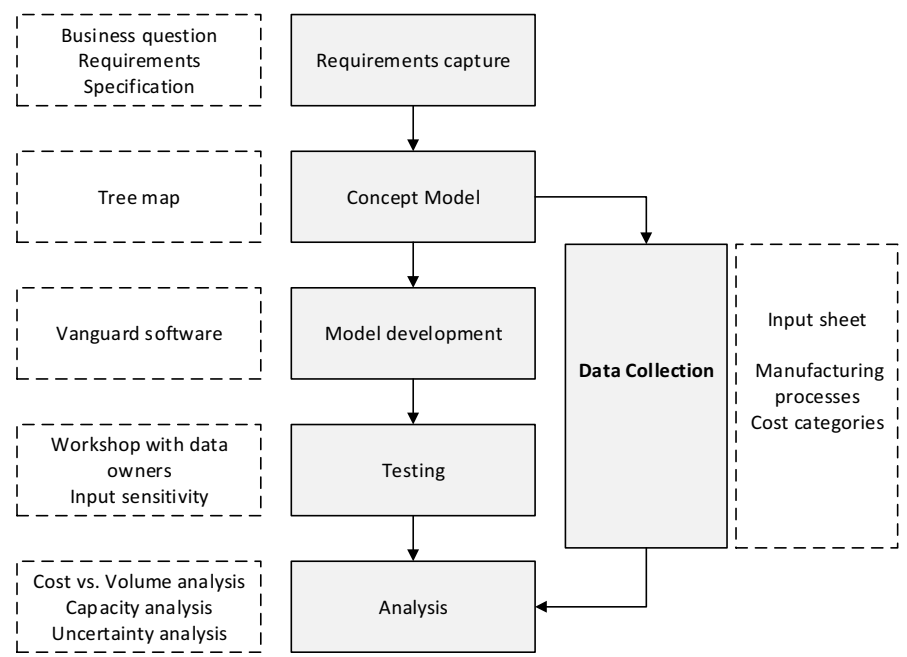

Figure 1. Use case methodology aligned with the generic approach.

The key business questions, for the use case, were defined as: What is the cost per part per process?; How does the cost per part compare with different processes?; Which technology is cost-effective at different volumes?; What level of investment is 
required for different processes?. The key performance indicator (KPI) has been identified as: cost per part produced per manufacturing process.

The process cost estimation concept model has been developed and visualised in a form of a tree map, provided below in Figure 2.

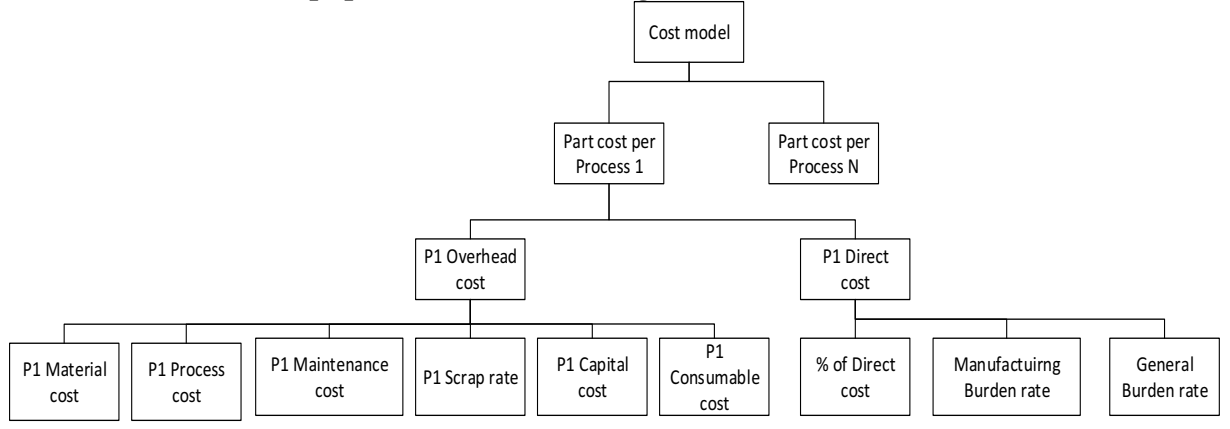

Figure 2. High level structure of a process cost model

Next, standard data inputs templates for scenarios have been developed covering assumptions and references to data sources.

The use case process cost estimation model was developed using Vanguard Studio software. For testing, a number of activities have been carried out: testing of the key functionality - sensitivity analysis on inputs; a workshop with key stakeholders, including the end user of the analysis, in order to validate the existing cost estimation model against the concept model.

The analysis of 4 composite manufacturing processes for a specific component in the automotive industry has been carried out, providing the following outputs: key cost drivers, sensitivity analysis, cost volume analysis and uncertainty analysis. Figures 3 and 4 provide snapshots of analysis. Cost volume analysis (Figure 3) provide ability to compare the impact of process scalability on cost, which can support process selection suitable for different scales of production. Uncertainty analysis (Figure 4) focuses on exploring how data uncertainty affects cost of part manufacturing by different process. This type of analysis allows to see what is a possible cost range that a part could cost.

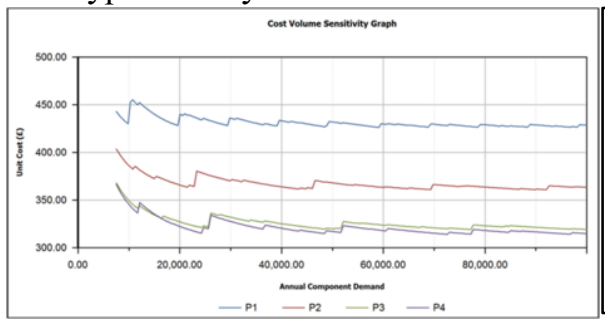

Figure 3. Cost vs. volume analysis

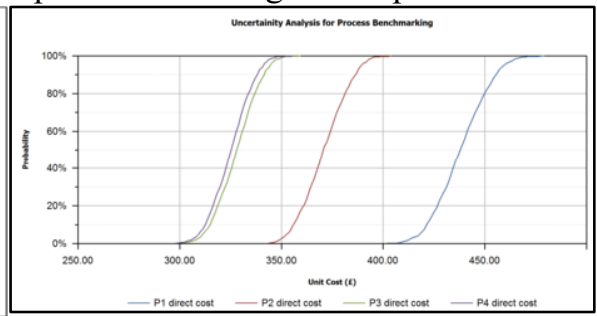

Figure 4. Uncertainty analysis example

\section{Conclusions}

In this paper, cost estimation guidelines were linked to modelling best practice to create a generic approach for cost estimation model development. The generic approach consists of 5 key steps: requirements capture, concept model, model development, testing, points and analysis. This approach can serve as a check list for estimators in 
ensuring that when developing and using models, appropriate level of detail for completeness is included.

The approach has been demonstrated on a use case of cost estimation for composites manufacturing for the automotive industry. Each step from the generic approach to cost estimation modelling has been outlined and then demonstrated via the use case. The use case provides insight into a practical application of the generic cost estimation modelling approach, using suitable detail so that the approach can be evaluated in terms of its credibility.

\section{Acknowledgements}

This work has been carried out as a part of Composites Large Transformation Project 2017-2018 funded by HVMC, Innovate UK and was developed in collaboration with MTC (Manufacturing Technology Centre), National Composite Centre (NCC), Advanced Manufacturing Research Centre (AMRC) and Warwick Manufacturing Group (WMG).

\section{References}

[1] Composites Leadership Forum (2016) Lightening the road, Delivering UK growth through multi-sector application of composites, The 2016 UK Composites Strategy, Composites Leadership Forum, Composites UK, Date accessed 28/09/2018, https://compositesuk.co.uk/system/files/documents/Strategy\%20final\%20version_1.pdf

[2] Mårtensson, P., Zenkert, D., Akermo, M., (2014) Integral or differential design for a cost effective automotive body structure, ECCM16 - 16th European Conference On Composite Materials, Seville, Spain, 22-26 June 2014.

[3] Fuchs, E.R.H., Field, F.R., Roth, R., Kirchain, R.E., (2008) Strategic materials selection in the automobile body: Economic opportunities for polymer composite design, Composites Science and Technology, 68(9), pp: 1989-2002.

[4] Schubel, P.J., (2011) Cost modelling in polymer composite applications. University of Nottingham.

[5] Shehab E., Wasim, A., (2012) Manufacturing Cost Modelling for Aerospace Composite Applications, The 19th ISPE International Conference on Concurrent Engineering - CE2012, Trier (Germany).

[6] Hagnell, M.K., Akermo, M., (2015) A composite cost model for the aeronautical industry: Methodology and case study, Composites Part B: Engineering, 79, pp.254-261.

[7] Turner, T.U., Harper, L.T., Rudd, C.D., (2008) Low-cost carbon-fibre-based automotive body panel systems: A performance and manufacturing cost comparison, Proceedings of the Institution of Mechanical Engineers Part D Journal of Automobile Engineering, 222(1), pp.53-63.

[8] Haffner, S.M., (2002) Cost modelling and design for manufacturing guidelines for advanced composite fabrication, Massachusetts Institute of Technology.

[9] Hailian, Y., Xiongqing, Y., (2010) Integration of Manufacturing Cost into Structural Optimization of Composite Wings, Chinese Journal of Aeronautics, 23(2010), pp. 670-676.

[10] Cheung, J.M.W, Scanlan, J.P., Wiseall, S.S., (2009) An Aerospace Component Cost Modelling Study for Value Driven Design, Proceedings of the 1st CIRP Industrial Product-Service Systems (IPS2) Conference, Cranfield University, 1-2 April 2009, pp.238-242.

[11] Curran, R., Raghunathan, S., Price, M., (2004) Review of aerospace engineering cost modelling: the genetic causal approach, Progress in Aerospace Sciences, 40(8), pp.487-534.

[12] Hueber Ch., Horejsi, K., Schledjewski, R., (2016) Review of cost estimation: methods and models for aerospace composite manufacturing, Advanced Manufacturing: Polymer \& Composites Science, 2(1), pp.1-14.

[13] U.S. GAO (2009) GAO Cost Estimating and Assessment Guide, Best Practices for Developing and Managing Capital Program Costs, March 2009, available at: https://www.gao.gov/new.items/d093sp.pdf

[14] NASA (2008) NASA Cost Estimating Handbook (CEH), available at: https://www.nasa.gov/ sites/default/files/files/01_CEH_Main_Body_02_27_15.pdf 